\title{
EL "CALVARIO" DE JIMENO
}

\author{
P O R \\ MANUEL ROMERO DE TERREROS \\ de la Real Academia de Bellae Artes de San Fernando
}

En el Catálogo de Pinturas (Sección Colonial) del "Museo Nacional de Artes Plásticas", que publicó el Palacio de Bellas Artes en 1934, se: lista, bajo el número 107, el boceto, debido al excelente pincel de don. Rafael Jimeno y Planes, que representa un "Calvario" y que actualmentese exhibe en una de las galerias de la antigua Academia de San Carlos, junto con el otro boceto del mismo autor, "El milagro del pocito". Ambos. están pintados al óleo sobre lienzo y miden, respectivamente, 0.465 por0.75 y 0.84 por 0.71 .

Don Manuel Toussaint, autor del Catálogo mencionado, describe someramente la primera pintura, diciendo: "Cristo acaba de ser crucificado; el buen ladrón le compadece; el malo echa llamas por la boca. Con una esponja al cabo de una vara, le van a dar de beber. La Virgen y los suyos. se contristan al pie de la Cruz." $\mathrm{X}$ agrega: "Este boceto fué desarrollado. en la capilla de la Escuela de Minería, donde aún existe."

Don Justino Fernández, por su parte, en El Arte Moderno en $M \dot{\varepsilon}-$ xico (1937), después de calificar a Jimeno de "delicado colorista y magnifico dibujante", afirma que estos bocetos styos son "de exquisita factura, superiores a las mismas pinturas de la capilla, que se conservan intactas".

Pero el caso es que el "Calvario" no existe, ni existió jamás, en el local mencionado. Las pinturas de Jimeno que se conservan (aunque desgraciadamente no intactas) en lo que fué preciosa capilla del Palacio de Minería, son la Virgen de Guadalupe sobre el altar, y la Asunción de Nuestra Señora y el Milagro del Pocito, en el plafond. 
E1 "Calvario" que desarrolló Jimeno y que se ajusta en casi todo al boceto respectivo, se encuentra actualmente en el antiguo oratorio del Nacional Monte de Piedad, convertido hoy en Museo Histórico de la Institución e instalado en la estancia que antiguamente fué Contaduria del Marquesado del Valle de Oaxaca. Es de grandes dimensiones, puesta que mide unos 4.50 de alto por 3.60 de ancho; está pintado sobre lienzo y la parte superior, que afectaba la forma de medio punto, tuvo desgraciadamente que cortarse para que cupiera en el marco que se le hizo sobre el altar. Este es de madera de nogal, de no muy feliz diseño, siguiendo el estilo vulgarmente llamado Luis Felipe, que estuvo en boga en México para toda clase de mobiliario, en tiempos de Santa Anna. Por su gran tanaño resulta esta pintura desproporcionada al lugar en que se encuentra y algunas de las figuras presentan un aspecto un tanto abocetado $o$, si se nos permite la frase, algo fuera de foco; pero hay que suponer que el cuadro fué ejecutado con la mira de que luciera en una iglesia grande, en donde había de verse a distancia. Quizás haya adornado originalmente uno de los muros de la capilla del Señor de Santa Teresa, antes del derrumbe de la cúpula ocasionado por el terremoto de 1845 , ya que sabemos que dicho santuario ostentaba otras pinturas de nuestro artista.

Las figuras de este cuadro se apartan por completo de las tradiciones de un Calvario, pues adenás del Señor y los dos ladrones, suman hasta diez y siete, entre adultos y niños. Las del primer término son de tamaño algo mayor que el natural. A la izquierda, al pie de la Cruz se ve a la Santísima Virgen transida de dolor, rodeada de varias otras personas (entre las cuales están, al parecer, San Pedro y San Juan), mientras que una mujer, desfallecida, está sentada en el suelo con su hijo en brazos $y$, detrás de ella; otro pequeñuelo lleva en hombros el martillo y las tenazas. A la derecha, la Magdalena se abraza al madero; y un sayón levanta en la punta de una lanza una esponja embebida en la hiel y vinagre que ntro le presenta en una vasija, escena que contempla un soldado romano a caballo, vuelto de espaldas. En segundo término, se ven dos soldados más a caballo y las lanzas de otros; y, al fondo, unos montículos con árboles y algunas construcciones en lontananza. El conjunto de la composición es realista y está dramáticamente concebido, el dibujo y los escorzos son excelentes, y el colorido vivo y adecuado. Al contrario de lo que ocurre con "El Milagro del Pocito", nos parece esta pintura superior con mucho al boceto respectivo que se conserva en la antigua Academia de San Carlos. 